\title{
KONVERSI LAHAN PERTANIAN PADA KORIDOR JALAN SOLO- YOGYAKARTA DI KABUPATEN KLATEN
}

\author{
S. Rahayu ${ }^{a}$, I.Rudiarto ${ }^{b}$, Pangi $^{c}$ \\ a Universitas Diponegoro, Indonesia, email: sri.yksmg@yahoo.com \\ ${ }^{b}$ Universitas Diponegoro, Indonesia, email: irudiarto@yahoo.com \\ ${ }^{c}$ Universitas Diponegoro, Indonesia, email: folder.pangi@gmail.com
}

30 April 2015

\section{Keywords:}

agricultural land

convertion, Klaten

Regency, Satellite

Imagery, GIS

\begin{tabular}{l} 
Info Artikel; \\
Diterima: \\
27 Maret 2015 \\
Hasil Revisi : \\
10 April 2015 \\
Disetujui: \\
25 April 2015 \\
Publikasi On-Line: \\
30 April 2015 \\
\hline Kata kunci: \\
konversi lahan \\
pertanian, Kabupaten \\
Klaten, citra satelit, \\
SIG
\end{tabular}

\begin{abstract}
Article Info;
Received:

27 March 2015

in revised form:

10 April 2015

Accepted:

25 April 2015

Available Online:

Abstract: This research aims to assess the conversion of agricultural land in the SoloYogyakarta corridor of Klaten Regency (Kabupaten) during 1994-2013. It is important because the Solo-Yogyakarta arterial road in Kabupaten Klaten affects the land use of the surrounding area. This research has used spatial analysis methods, i.e. interpreting the Landsat and ALOS satellite imageries, overlaying land use maps, and comparing the land use map and the spatial plan map (RTRW) of Kabupaten Klaten. The results show that conversion of agricultural land during the period of 1994-2013 was 424.82 ha, most of which was converted into residential and industrial use. So, the average loss of agricultural land has been about 22.35 ha/year while residential land has increased by 19.84 ha/year. The largest conversion happened in the Banaran Village. Meanwhile, land use that was not in accordance with the RTRW was 69.15 ha (0.90\%). (C) 2015 GJGP UNDIP. All rights reserved.
\end{abstract}

\begin{abstract}
Abstrak: Keberadaan Jalan Solo-Yogyakarta di Kabupaten Klaten mempengaruhi penggunaan lahan di daerah sekitarnya. Penelitian ini bertujuan untuk mengkaji konversi lahan pertanian di koridor jalan tersebut dalam kurun waktu 1994-2013. Analisis spasial dilakukan dengan cara interpretasi Citra Landsat dan ALOS, tumpang susun (overlay) peta penggunaan lahan yang dihasilkan, serta pembandingan peta penggunaan lahan dengan Peta Rencana Tata Ruang Wilayah (RTRW) Kabupaten Klaten. Hasil penelitian menunjukkan konversi lahan pertanian selama tahun 1994-2013 mencapai 424,82 Ha, sebagian besar lahan tersebut berubah menjadi lahan permukiman dan industri. Laju penyusutan lahan pertanian mencapai 22,35 $\mathrm{Ha/tahun,} \mathrm{sedangkan} \mathrm{lahan} \mathrm{permukiman} \mathrm{meningkat} \mathrm{19,84} \mathrm{Ha/tahun.} \mathrm{Konversi} \mathrm{lahan}$ pertanian terbesar terjadi di Desa Banaran. Secara keseluruhan, penggunaan lahan yang tidak sesuai dengan RTRW Kabupaten Klaten mencapai 69,15 Ha (0,90\%).\%). (C) 2015 GJGP UNDIP. All rights reserved.
\end{abstract}

\section{PENDAHULUAN}

Proses pembangunan yang ada, tingginya laju pertumbuhan penduduk dan aktivitas manusia yang semakin meningkat akan mempengaruhi penggunaan lahan pertanian yang ada di suatu wilayah. Selain itu, penggunaan lahan yang ada di suatu wilayah juga dipengaruhi oleh keberadaan prasarana dan sarana, khususnya prasarana dan sarana transportasi. Salah satu pengaruhnya adalah mendorong terjadinya 
konversi lahan pertanian ke penggunaan non pertanian seperti untuk permukiman, industri, jasa dan lain sebagainya.

Konversi lahan pertanian menyebabkan penyempitan luas lahan pertanian yang ada. Semakin sempitnya luas lahan pertanian yang ada dan masih besarnya penduduk yang menggantungkan hidupnya dari lahan pertanian akan dapat menyebabkan pembangunan pertanian menghadapi masalah yang berat di masa yang akan datang. Hal ini dapat menyebabkan ketahanan pangan terganggu. Permasalahan ini tidak dapat dibiarkan dan harus mendapat perhatian yang sebaik-baiknya. Lahan pertanian perlu dijaga kelestariannya agar mampu menunjang proses pembangunan yang bersifat jangka panjang. Salah satu usaha yang dapat dilakukan untuk mengembangkan sektor pertanian adalah dengan cara melindungi lahan pertanian yang produktif agar tidak beralih ke penggunaan lahan non pertanian.

Sebagai daerah yang lokasinya sangat strategis, daerah sepanjang Koridor Jalan Solo-Yogyakarta di Kabupaten Klaten merupakan salah satu daerah yang mengalami penyusutan lahan pertanian. Penyusutan lahan pertanian ini terjadi seiring dengan pertambahan penduduk dan proses pembangunan yang ada di sepanjang koridor tersebut. Menurut topografinya, koridor Jalan Solo-Yogyakarta ini merupakan wilayah yang datar. Sedangkan dari jenis tanahnya, daerah ini merupakan daerah yang subur dan produktif, sehingga sangat disayangkan apabila lahan pertanian yang subur terkonversi menjadi lahan non pertanian.

Penelitian ini bertujuan untuk mengkaji konversi lahan pertanian di Koridor Jalan Solo-Yogyakarta, Kabupaten Klaten. Konversi lahan pertanian yang ada dilakukan dengan memanfaatkan citra penginderaan jauh dan Sistem Informasi Geografis (SIG). Pemanfaatan Citra satelit dikarenakan citra satelit dapat menyajikan gambaran obyek, daerah dan gejala di permukaan bumi secara lengkap dengan wujud dan letak obyek yang mirip dengan keadaan sebenarnya di medan (Sutanto, 1986).

\section{DATA DAN METODE}

Wilayah penelitian meliputi desa-desa di sepanjang Jalan Solo - Yogyakarta yang berada di Kabupaten Klaten yang terkena pengaruh dari adanya jalur utama tersebut yang meliputi 59 desa di 11 kecamatan.

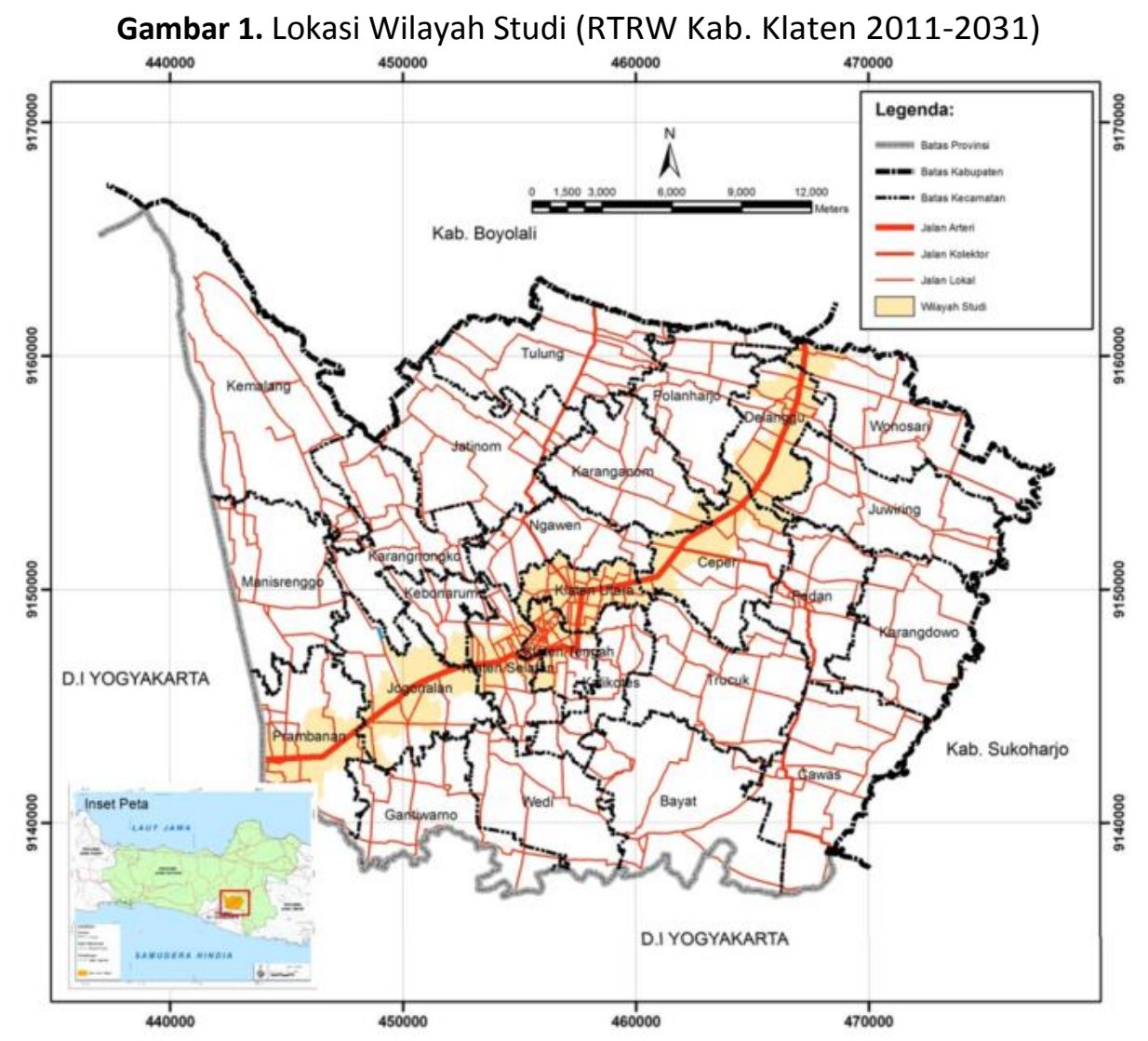


Tabel 1. Daftar Desa/Kelurahan Wilayah Studi (RTRW Kab. Klaten 2011-2031)

\begin{tabular}{|c|c|c|c|c|c|}
\hline No & Kecamatan & Desa & No & Kecamatan & Desa \\
\hline 1 & \multirow[t]{7}{*}{ Prambanan } & Kebon Dalem Kidul & 31 & \multirow[t]{7}{*}{ Delanggu } & Butuhan \\
\hline 2 & & Kotesan & 32 & & Banaran \\
\hline 3 & & Sanggrahan & 33 & & Karang \\
\hline 4 & & Geneng & 34 & & Delanggu \\
\hline 5 & & Kemudo & 35 & & Sabrang \\
\hline 6 & & Taji & 36 & & Gatak \\
\hline 7 & & Tlogo & 37 & & Kepanjen \\
\hline 8 & Kebonarum & Gondang & 38 & Karanganom & Blanceran \\
\hline 9 & \multirow[t]{9}{*}{ Jogonalan } & Somopuro & 39 & Klaten selatan & Trunuh \\
\hline 10 & & Tangkisan Pos & 40 & & Sumberejo \\
\hline 11 & & Gondangan & 41 & & Merbung \\
\hline 12 & & Bakung & 42 & & Tegalyoso \\
\hline 13 & & Karangdukuh & 43 & & Gayamprit \\
\hline 14 & & Plawikan & 44 & & Jetis \\
\hline 15 & & Kraguman & 45 & Klaten tengah & Buntalan \\
\hline 16 & & Prawatan & 46 & & Mojayan \\
\hline 17 & & Wonoboyo & 47 & & Bareng \\
\hline 18 & \multirow[t]{8}{*}{ Ceper } & Mlese & 48 & & Semangkak \\
\hline 19 & & Jombor & 49 & & Kabupaten \\
\hline 20 & & Dlimas & 50 & & Klaten \\
\hline 21 & & Jambu Kulon & 51 & & Tonggalan \\
\hline 22 & & Meger & 52 & Klaten utara & Sekarsuli \\
\hline 23 & & Klepu & 53 & & Bareng lor \\
\hline 24 & & Ngawonggo & 54 & & Karanganom \\
\hline 25 & & Kuncen & 55 & & Ketandan \\
\hline 26 & \multirow[t]{2}{*}{ Wonosari } & Wadung Getas & 56 & & Belang Wetan \\
\hline 27 & & Tegalgondo & 57 & & Jonggrangan \\
\hline 28 & \multirow[t]{3}{*}{ Delanggu } & Bowan & 58 & & Gergunung \\
\hline 29 & & Dukuh & 59 & & Jebugan \\
\hline 30 & & Jetis & & & \\
\hline
\end{tabular}

Pendekatan yang digunakan dalam penelitian ini adalah pendekatan diskriptif kuantitatif. Pemetaan penggunaan lahan di daerah penelitian dilakukan dengan interpretasi citra satelit Landsat dan citra satelit ALOS. Interpretasi citra dilakukan dengan menggunakan Software ER Mapper 7.0. Sedangkan pengolahan dan analisis data dilakukan dengan menggunakan bantuan program SIG yaitu sofware ARC GIS. Pengolahan dan analisis data dalam penelitian ini meliputi:

a) Identifikasi penggunaan lahan tahun 1994 dan 2013

Identifikasi penggunaan lahan dilakukan dengan menginterpretasi citra satelit tahun 1994 dan tahun 2013. Interpretasi Citra Satelit adalah upaya pengenalan obyek yang tergambar pada citra satelit dan penilaian arti pentingnya obyek tersebut (Sutanto, 1986). Guna mengecek kebenaran hasil interpretasi citra maka dilakukan survai atau cek ke lapangan secara langsung. Survai lapangan ini juga untuk mengumpulkan data yang tidak dapat diperoleh dari citra satelit. Untuk melihat citra daerah penelitian yang telah di Cropping, dapat dilihat pada Gambar 2. 
Gambar 2. Citra daerah penelitian yang telah di Cropping (Hasil Analisis, 2013)

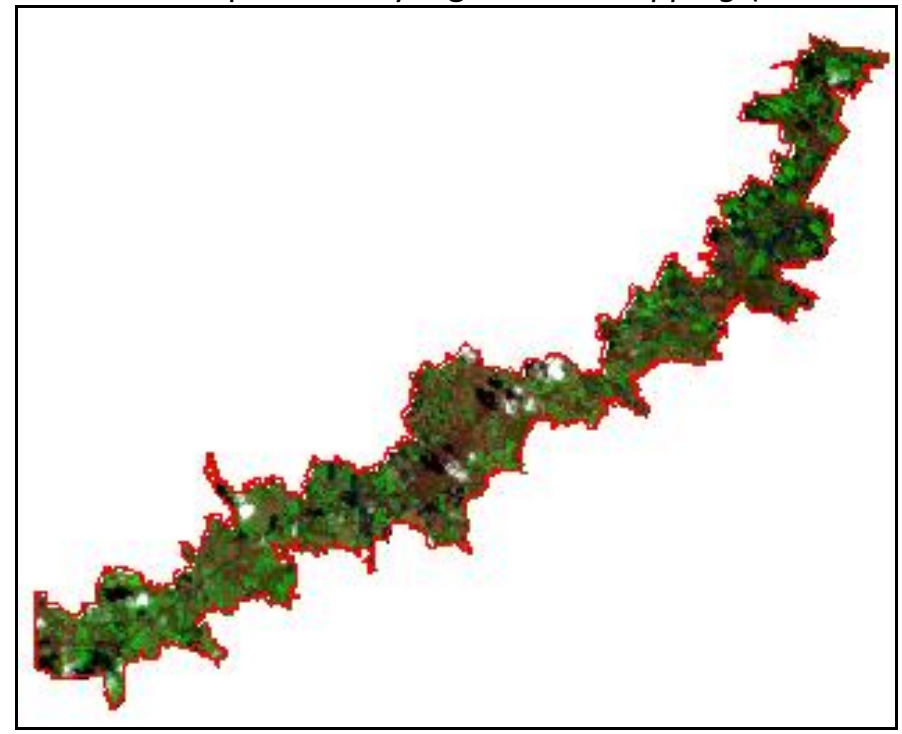

b) Analisis konversi lahan pertanian

Analisis ini dilakukan dengan mengoverlay Peta Penggunaan Lahan di Koridor Jalan Solo-Yogyakarta Kabupaten Klaten tahun 1994 dengan Tahun 2013 yang diperoleh dari interpretasi citra satelit. Hasil overlay adalah Peta Perubahan Penggunaan Lahan Pertanian di Koridor Jalan Solo-Yogyakarta Kabupaten Klaten antara tahun 1994 -2013. Dengan analisis spasial pada peta tersebut, akan diketahui luas dan distribusi spasial perubahan penggunaan lahan pertanian yang terjadi.

c) Analisis Penggunaan Lahan dengan Rencana Tata Ruang Wilayah (RTRW) Kabupaten Klaten.

Analisis ini dilakukan untuk mengetahui apakah penggunaan lahan yang ada sesuai dengan peruntukan lahannya. Analisis ini dilakukan dengan mengoverlay Peta Penggunaan Lahan yang telah dihasilkan dengan Peta Rencana Pola Ruang Kabupaten Klaten Tahun 2011-2031.

\section{HASIL DAN PEMBAHASAN}

3.1. Identiikasi Penggunaan Lahan Tahun 1994 dan 2013

Hasil klasifikasi penggunaan lahan dari citra landsat dihasilkan 5 jenis penggunaan lahan yang berada di wilayah studi yaitu penggunaan lahan industri, permukiman, lahan terbuka, lahan pertanian dan vegetasi lain.

Gambar 3. Peta Penggunaan Lahan Tahun 1994

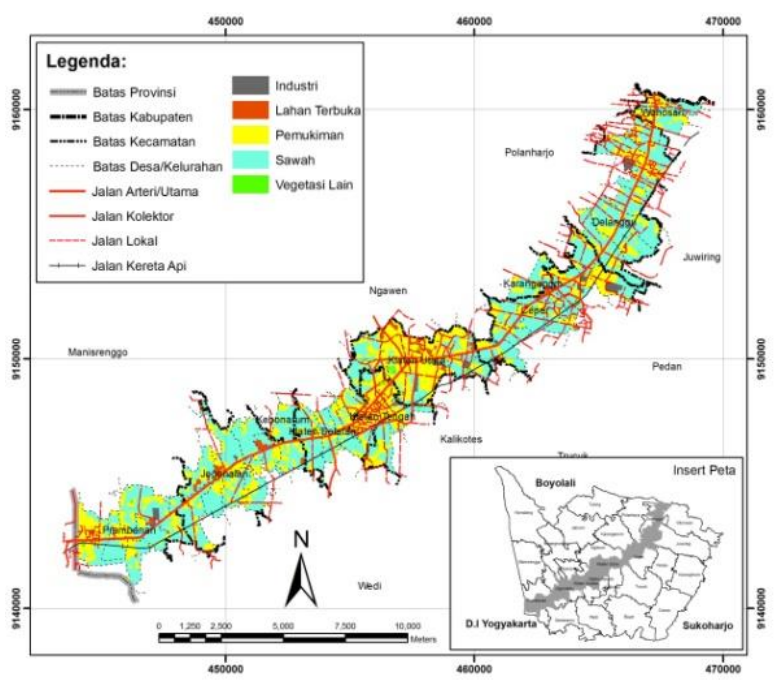

Gambar 4. Peta Penggunaan Lahan Tahun 2013

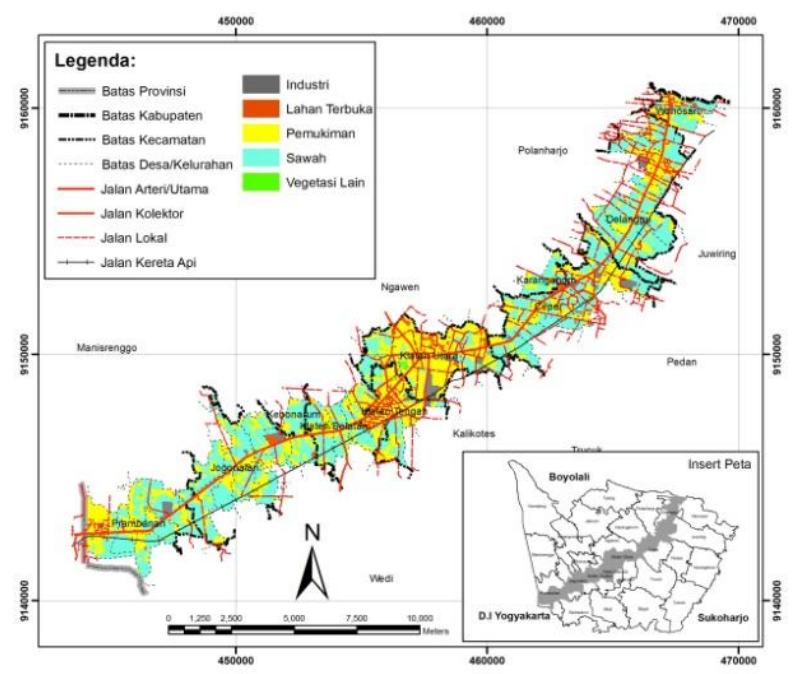


Penggunaan lahan di Koridor Jalan Solo-Yogyakarta yang berada di Kabupaten Klaten pada tahun 1994 di dominasi oleh penggunaan lahan sawah yaitu 4.248,55 Ha atau 55,23 \%. Sedangkan penggunaan lahan untuk permukiman sebesar 3.095,11 Ha atau 40,24\%. Penggunaan lahan untuk permukiman yang luas ada di Kecamatan Klaten Utara dan Kecamatan Klaten Tengah.

Tabel 2. Jenis dan Luasan Penggunaan Lahan Tahun 1994 (Hasil Analisis, 2013)

\begin{tabular}{llrr}
\hline No & Jenis Penggunaan Lahan & Luas $(\mathrm{Ha})$ & Prosentase \\
\hline $\mathbf{1}$ & Industri & 113.30 & 1,47 \\
$\mathbf{2}$ & Lahan Terbuka & 146.77 & 1,91 \\
$\mathbf{3}$ & Pemukiman & 3095.11 & 40,24 \\
$\mathbf{4}$ & Pertanian & 4248.55 & 55,23 \\
$\mathbf{5}$ & Vegetasi Lain & 88.53 & 1,15 \\
& Jumlah Total & $\mathbf{7 6 9 2 . 2 6}$ & $\mathbf{1 0 0 , 0 0}$ \\
\hline
\end{tabular}

Pada tahun 2013, penggunaan lahan pertanian di daerah penelitian masih mendominasi yaitu $49,71 \%$, lahan permukiman 45,14 \% dan penggunaan lahan lainnya tidak banyak mengalami perubahan Luasan untuk masing-masing jenis penggunaan lahan dijelaskan pada tabel berikut ini:

Tabel 3. Jenis dan Luasan Penggunaan Lahan Tahun 2013 (Hasil Analisis, 2013)

\begin{tabular}{llrr}
\hline No & Jenis Penggunaan Lahan & Luas $(\mathbf{H a})$ & Prosentase \\
\hline $\mathbf{1}$ & Industri & 196.16 & 2,55 \\
$\mathbf{2}$ & Lahan Terbuka & 109.41 & 1,42 \\
$\mathbf{3}$ & Pemukiman & 3472.2 & 45,14 \\
$\mathbf{4}$ & Pertanian & 3823.73 & 49,71 \\
\hline $\mathbf{5}$ & Vegetasi Lain & 90.76 & 1,18 \\
& Jumlah & $\mathbf{7 6 9 2 . 2 6}$ & $\mathbf{1 0 0}$ \\
\hline
\end{tabular}

3.2. Konversi Lahan Pertanian dari Tahun 1994 sampai 2013

Konversi lahan pertanian di peroleh dari hasil overlay Peta penggunaan lahan daerah penelitian tahun 1994 dan peta penggunaan lahan tahun 2013. Besarnya konversi lahan di sajikan dalam Tabel 4.

Tabel 4. Perubahan Penggunaan Lahan (Konversi) Pertanian di Koridor Solo - Yogya, Kab. Klaten (Hasil Analisis, 2013)

\begin{tabular}{|c|c|c|c|c|c|}
\hline \multirow[t]{2}{*}{ No } & \multirow{2}{*}{ Jenis Penggunaan Lahan } & \multicolumn{2}{|c|}{$\begin{array}{c}\text { Luas Lahan pada } \\
\text { Tahun }\end{array}$} & \multirow{2}{*}{$\begin{array}{l}\text { Perubahan } \\
\text { Penggunaan } \\
\text { Lahan (Ha) }\end{array}$} & \multirow{2}{*}{$\begin{array}{c}\text { Rata-rata } \\
\text { Perubahan } \\
\text { pertahun (Ha) }\end{array}$} \\
\hline & & 1994 & 2013 & & \\
\hline 1 & Industri & 113.30 & 196.16 & 82.86 & 4.36 \\
\hline 2 & Lahan Terbuka & 146.77 & 109.41 & -37.36 & -1.96 \\
\hline 3 & Pemukiman & 3095.11 & 3472.2 & 377.09 & 19.84 \\
\hline 4 & Pertanian & 4248.55 & 3823.73 & -424.82 & -22.35 \\
\hline \multirow[t]{2}{*}{5} & Vegetasi Lain & 88.53 & 90.76 & 2.23 & 0.12 \\
\hline & Jumlah & 7692.26 & 7692.26 & & \\
\hline
\end{tabular}


Gambar 5. Grafik Perubahan Lahan di Koridor Jalan Solo-Yogyayakarta, Kab. Klaten

(Hasil Analisis, 2013)

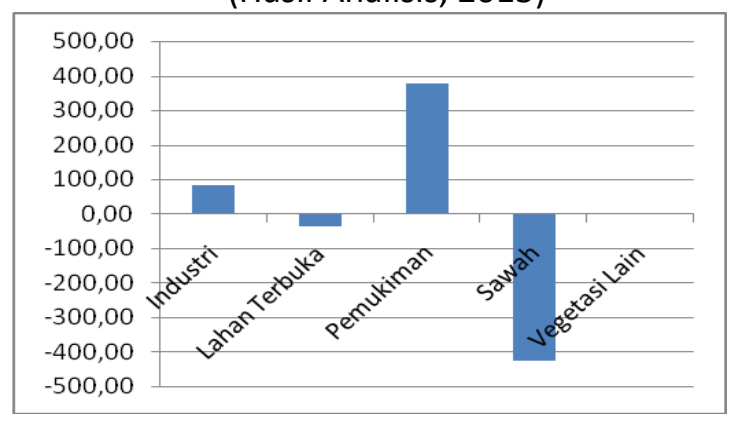

Berdasarkan Tabel 4 diatas dapat diketahui bahwa selama periode 1994 - 2013 perubahan penggunaan lahan yang paling besar adalah lahan untuk pertanian yaitu berkurang sebesar $424.82 \mathrm{Ha}$ atau berkurang 9,99 \% dibandingkan luas lahan pertanian pada tahun 1994. Rata-rata penyusutan lahan pertanian adalah sebesar -22,35 Ha/tahun, Besarnya konversi lahan pertanian tersebut harus mendapatkan perhatian, karena hal ini tentunya akan dapat mengancam usaha untuk mencapai ketahanan pangan. Disamping itu juga dikarenakan lahan pertanian yang ada di Koridor Jalan SoloYogya ini mayoritas merupakan lahan pertanian yang subur.

Penyusutan luas lahan pertanian yang ada di daerah penelitian karena berubah ke penggunaan lahan lain diantaranya adalah berubah ke lahan permukiman sebesar $377.09 \mathrm{Ha}$ (rata-rata penambahan adalah 19,84 Hatahun). Besarnya pertambahan luas lahan pertanian ini disebabkan karena pertambahan jumlah penduduk yang ada. Disamping itu juga disebabkan daya tarik yang ada di daerah penelitian diantaranya adalah:

- Daerah penelitian merupakan daerah yang relatif datar, sehingga aman dari bencana alam seperti longsor bahkan juga aman dari bahaya banjir.

- Memiliki aksesibilitas yang baik, karena daerah ini dilalui jalan utama yang menghubungkan Kota Solo dan Provinsi Yogyakarta. Aksesibilitas didaerah ini juga didukung oleh moda transportasi angkutan umum yang banyak.

- Kedalaman air yang relatif dangkal dan kualitas airnya yang cukup baik.

Perubahan penggunaan lahan yang lain adalah perubahan lahan industri yang rata-rata bertambah setiap tahunnya sejumlah 4,36 $\mathrm{Ha}$, lahan untuk vegetasi lain bertambah 0,12 $\mathrm{Ha}$ /tahun serta lahan terbuka berkurang 1,96 Ha/tahun. Lokasi konversi lahan pertanian yang terjadi di Koridor Solo-Yogyakarta tersebut di gambarkan dalam peta konversi lahan pertanian sebagai berikut ini.

Gambar 6. Peta Sebaran Lokasi Konversi Lahan Pertanian di Koridor Solo-Yogyakarta Periode Tahun 1994-2013 (Hasil Analisis, 2013)

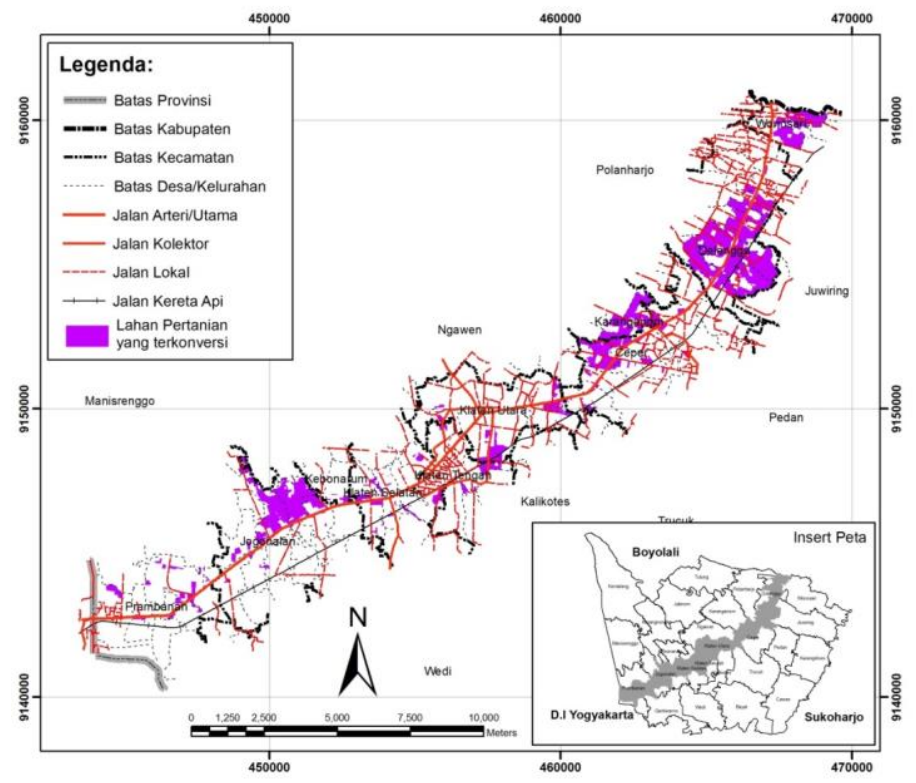


Desa yang paling besar mengalami konversi lahan pertanian adalah Desa Banaran Kecamatan Delangu. Konversi lahan pertanian yang ada di daerah ini diantaranya berubah menjadi permukiman, perdagangan dan jasa, pom bensin bahkan gudang. Gudang yang ada di desa ini adalah gudang Alfamart. Pembangunan gudang ini juga memicu konversi lahan-lahan sawah yang ada disekitarnya. Lahan sawah yang berada di belakang gudang ini pada saat ini sudah berubah menjadi perumahan. Selain itu juga harga lahan menjadi naik karena sudah terbangunnya beberapa fasilitas yang ada disekitarnya khususnya jalan. Hal ini lebih lanjut dapat memicu terjadinya transaksi jual beli sawah yang ada disekitarnya.

Konversi lahan yang terjadi di daerah penelitian perlu memdapat perhatian, khususnya tingginya konversi lahan pertanian ke non pertanian yang didominasi berubah ke lahan permukiman. Mengingat lahan pertanian di daerah penelitian merupakan lahan pertanian yang subur. Hal ini perlu dipertimbangkan karena setiap kebijakan pembangunan yang ada harus berwawasan lingkungan dan berkelanjutan.

\subsection{Kesesuaian Penggunaan Lahan dengaN RTRW Kabupaten Klaten}

Sampai pada tahun 2013, sebagian besar (9910 \%) penggunaan lahan di sepanjang Koridor SoloYogyakarta, Kabupaten Klaten masih sesuai dengan Rencana Pola Ruang Kabupaten Klaten tahun 2011 - 2031. Jumlah tersebut di mungkinkan akan berkurang jika pemanfaatan lahan di koridor ini tidak di monitoring dengan ketat. Perlu langkah antisipasi oleh pemerintah setempat agar pembangunan yang dilakukan di masa yang akan datang lebih diarahkan ke lahan-lahan yang bukan merupakan lahan sawah, khusunya sawah yang beririgasi.

Tabel 5. Kesesuaian Lahan dengan RTRW Kabupaten Klaten (Hasil Analisis, 2013)

\begin{tabular}{lrr}
\hline \multicolumn{1}{c}{ Kesesuaian } & \multicolumn{1}{c}{ Luas (Ha) } & Prosentase \\
\hline Sesuai & 7623.11 & $99.10 \%$ \\
Tidak Sesuai & 69.15 & $0.90 \%$ \\
Jumlah & $\mathbf{7 6 9 2 . 2 6}$ & $\mathbf{1 0 0 \%}$ \\
\hline
\end{tabular}

Gambar 7. Lokasi Sebaran Konversi Lahan yang Tidak sesuai dengan RTRW (Hasil Analisis, 2013)

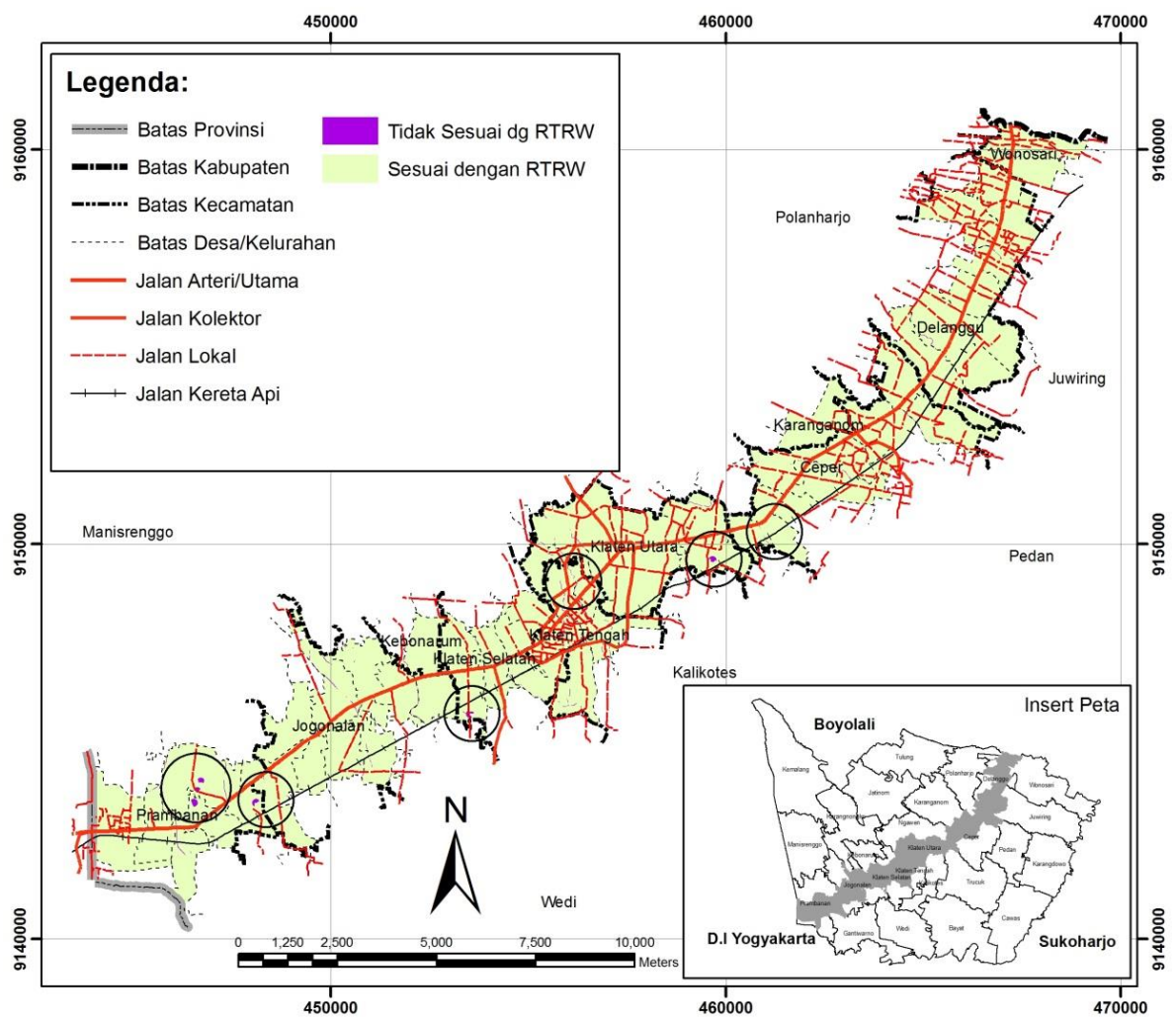




\section{KESIMPULAN}

Berdasarkan hasil analisis dapat disimpulkan bahwa keberadaan Jalan Solo-Yogya dan peningkatan aksesibilitas pada ruas jalan tersebut ternyata merupakan daya tarik di daerah penelitian yang pada akhirnya memicu terjadinya konversi lahan. Selama periode tahun 1994 sampai 2013 lahan pertanian di koridor tersebut berkurang sebesar $424.82 \mathrm{Ha}$, dengan rata-rata perubahan pertahun $22,35 \mathrm{Ha}$ /tahun. Sebagian besar lahan pertanian berubah ke lahan permukiman sebesar 377.09 ha, dengan rata-rata bertambah $19.84 \mathrm{Ha}$ /tahun. Desa yang mengalami perubahan lahan pertanian terbesar adalah Desa Banaran di Kecamatan Delanggu.

Kesesuaian penggunaan lahan di daerah penelitian dengan Peta Rencana Tata Ruang Kabupaten Klaten diketahui bahwa lahan yang penggunaanya tidak sesuai dengan RTRW Kabupaten Klaten adalah sebesar 69.15 ha (0.90\%). Berdasarkan hasil penelitian tersebut maka ke depan perlu memperketat aturan pemberian ijin pendirian bangunan di atas lahan pertanian, khususnya lahan pertanian yang subur.

\section{DAFTAR PUSTAKA}

Aronoff, S. (1989). Geographic Information Systems : A management Perspective. WDL Publ., Ottawa.

Buiten, H.J. (1993). Image Interpretation : Visual or Digital? Dalam : Buiten, H.J. dan J.G.P.W. Clevers (Eds), Land Observation by Remote Sensing : Theory and Applications. Gordon and Breach Science Publ. Amterdam.

Bing Hui, dkk. (2012). Analysis Of Land Use Change Characteristics Based On Remote Sensing and GIS In The Jiuxiang River Watershed. Dalam Internasional Journal On Smart Sensing and Interlligent Systems, Vol. 5, No, 4. Bulan Desember 2012. Diakses tanggal 10 Maret 2013.

Danoedoro, P. (1996). Pengolahan Citra Digital : Teori dan Aplikasi Dalam Bidang Penginderaan Jauh. Fakultas Geografi Universitas Gadjah Mada, Yogyakarta.

Hord, R.M. (1986). Remote Sensing Methods and Applications. John Wiley \& Sons, New york.

Jensen, J.R. (1983). Urban/Suburban Land Use Analysis. Dalam Colwell, R.N., Manual of Remote Sensing. Vol II, American Society of Photogrammetry, Virginia.

Jensen, J.R. (1996). Introductory Digital Image Processing : A Remote Sensing Perspective, Second Edition. Prentice Hall, New Jersey.

Lillesand, T.M. dan R.W. Kiefer. (1979). Remote Sensing and Image Interpretation. Terjemahan : Dulbahri, P. Suharsono, Hartono dan Suharyadi, 1990. Gadjah Mada University Press, Yogyakarta.

Lindgren, D.T. (1985). Land Use Planning and Remote Sensing. Martinus Nijhoff Publishers, Dordrecht.

Mengistu D. A. Dan AyobamiT. (2007). Application of Remote Sensing and GIS inland Use/Land Cover Mapping and Change Detection in a Part of South Western Nigeria. Dalam Journal: African Journal of Environmental Science and Technology Vol. 1 (5), pp. 099-109, December, 2007. Diakses tanggal 10 Maret 2013

Meyer, W.B. dan Turner II.L. (1994). Changes in Land Use and Land Cover A global Perspective. Cambridge University Press, Cambridge.

Purwadhi, S. H. (2001). Interpretasi Citra Digital. Gramedia, Jakarta.

Sitorus, S.R.P. (1995). Evaluasi Sumberdaya Lahan. Tarsito, Bandung.

Sutanto. (1986). Penginderaan Jauh Jilid 1. Gadjah Mada University Press, Yogyakarta.

Warpani, Suwardjoko. (1990). Merencanakan Sistem Perangkutan. Bandung. Penerbit ITB Bandung. 